Patricia Villaseñor Cuspinera

\title{
Natura et arbitrium: en torno a la etimología y a la significación de las palabras en Isidoro de Sevilla
}

En el capítulo 29 del Libro I de sus Etimologías, San Isidoro de Sevilla explica de esta manera lo que para él es la etimología:

La etimología es el origen de los vocablos, ya que la fuerza de una palabra o de un nombre se comprende por su interpretación. ${ }^{1}$

Sin embargo, parece que la fuerza (vis), el sentido de las palabras, sólo puede encontrarse dentro de un mensaje determinado. Como dice Gadamer:

La significación del objeto sólo es un primer objetivo del entender; posteriormente, el entender se dirige a lo que quiere decir el emisor del mensaje (Wahrheit und Methode, p. 278).

Las palabras sin duda significan algo, pero su sentido, se dice, está dado no por su significado literal, sino por el valor

${ }^{1}$ Isid., Etym., I.29.1: Etimología est origo vocabulorum, cum vis verbi vel nominis per interpretationem colligitur. 
que adquieren dentro de un texto. No hablamos para que se comprendan los "nombres" que pronunciamos; no hablamos (al menos, fuera de las clases), de acuerdo con la etimología de las palabras, sino para comunicarnos con los otros.

Isidoro añade:

Cuando se ve de dónde ha surgido un nombre, se entiende más rápidamente su fuerza. Pues todo examen de una cosa es más sencillo si se conoce su etimología. ${ }^{2}$

¿Sirve realmente para ello la etimología? Dicho de otro modo, ¿por qué utilizamos las etimologías para determinar el significado de las cosas? ¿De qué sirve saber, por ejemplo, que "hecatombe" significa "(sacrificio) de cien bueyes", si ya en Homero, Aquiles narra que Peleo había ofrecido una "hecatombe de cincuenta corderos"? 3

Dice Isidoro:

Pero no todos los nombres fueron impuestos por los antiguos según su naturaleza, sino que algunos también lo fueron según el antojo, así como nosotros, a nuestros esclavos y a nuestras posesiones, a veces les damos nombres según lo que agrada a nuestra voluntad. Por ello no se encuentran las etimologías de todos los nombres, porque algunos tomaron sus vocablos no según la cualidad con que fueron engendrados, sino de acuerdo con el arbitrio de la voluntad humana. ${ }^{4}$

2 Isid., Etym., I.29.2: Nam dum videris unde ortum est nomen, citius vis eius intellegis. Omnis enim rei inspectio etymologia cognita plenior est. Díaz y Díaz, en su "Introducción general" a las Etimologías (p. 163), dice que la obra "constituye una especie de explicación por procedimientos lingüísticos de cuanto existe, y sirve a la vez como modo de conocer y comprender mejor el universo, y como recurso profundo para una más correcta y completa inteligencia de los textos antiguos..."

${ }^{3}$ Il. XXIII, 146-147; cfr. vv. 864 y 873.

4 Isid., Etym., I.29.2-3: Non autem omnia nomina a veteribus secundum naturam imposita sunt, sed quaedam et secundum placitum, sicut et nos servis et 
De las palabras de San Isidoro se desprende que se creía en una relación, natural o arbitraria, entre las cosas y sus nombres, y que esa relación se encontraba en o mediante la etimología (symbolon, para Aristóteles; adnotatio, para Cicerón). Es decir, era posible tratar simbólicamente los objetos. Sin embargo, antes de seguir adelante, es necesario hacer una síntesis de lo que han dicho los estudiosos sobre la "significación de las cosas".

Ya muchos han hablado acerca de las relaciones entre signos (que presentan objetos) y objetos (que se presentan mediante signos): diversas teorías linguiísticas se han elaborado alrededor de este tema; piénsese, abusiva y esquemáticamente, en el naturalismo, en el convencionalismo y en el pragmatismo. Isidoro (y quizá la mayor parte de los hombres de la Antigüedad y de la Edad Media) se adheriría gustoso a lo que puede llamarse "naturalismo" dentro de una semántica realista, cuyo postulado, en forma muy general, sería el siguiente: el significante (la expresión) hace conocer el significado (el contenido) del signo; la forma del signo es afín a su sentido. La teoría se encuentra por primera vez en Platón, en el Cratilo (384b), y, de acuerdo con ella, los signos se dan physei, es decir, por naturaleza.

Según la segunda teoría, el "convencionalismo", cuyo origen puede remontarse al Platón de la Séptima Carta (343a y b), los signos son convencionales (thesei); están en lugar de representaciones de objetos; es decir, los signos expresan conceptos referentes a representaciones de objetos.

Finalmente, la tercera teoría, la que podría llamarse "pragmática", postula que los signos sólo se dan en una situación determinada: el sentido de un enunciado concierne, pues, a la

possessionibus interdum secundum quod placet nostrae voltti nomina damus. Hinc est quod omnium nominum etymologiae non reperiuntur, quia quaedam non secundum qualitatem, qua genita sunt, sed iuxta arbitrium humanae voluntatis vocabula acceperunt... 
situación en la que este enunciado se emplea, y son los usuarios de los signos los que hacen posible la significación. ${ }^{5}$ Las palabras, según dice Horacio, cambian de sentido casi al arbitrio del vulgo:

renacerán muchos vocablos que ya han caído, y caerán los que ahora están en el honor, si el uso lo quiere, en cuyo arbitrio está el derecho y la norma de hablar. ${ }^{6}$

En cierto sentido, esto lo había dicho ya Gorgias. Pedro Tapia, en su diálogo entre Sócrates y Gorgias, ${ }^{7}$ y haciendo alusión a los fragmentos del sofista, ${ }^{8}$ hace decir a Gorgias que el orador debe...

hacer que las palabras signifiquen lo mismo en el oyente y en el hablante. A eso llamo kairós, prepon... Hay que tener presente la opinión del otro... se trata de que los interlocutores lleguen a estar en una situación tal, que interpreten las palabras de la misma manera y tengan la misma disposición anímica; de que, para esto, el que habla tenga en cuenta la situación concreta en que se encuentra a la hora de las palabras, y de ver que a esa situación pertenece... el estado anímico en que se encuentra el oyente... se trata de calcular la oportunidad de las palabras... En pocas palabras, el orador, me refiero

${ }^{5}$ Luisa Puig, La realidad ausente, p. $12 n$.

${ }^{6}$ Ars Poetica 70-72: multa renascentur quae iam cecidere, cadentque / quae nunc sunt in honore vocabula, si volet usus, / quem penes arbitrium est et ius et norma loquendi.

7 Tapia Zúñiga, Pedro C., “Gorgias, más allá del bien y del mal”, pp. 48-49.

8 Gorgias, fr. 6 (p. 8): "lo conveniente, cuando conveniente, decir y callar y hacer y omitir"; fr. 13 (p. 26): "Nadie, ni retórico ni filósofo, hasta hoy, ha definido el arte del tiempo oportuno, ni quien intentó el primero escribir sobre el mismo, Gorgias el leontino...". Anaxarco, en su tratado Acerca de la realeza (D-K 72, B1, t. II, p. 239-240), dice que "uno debe conocer la medida de la oportunidad; éste es, en efecto, el término de la sabiduría". Cfr. también Aris., Reth., 1408b 1-2. 
en general al que habla, calculando tiempos, lugares y circunstancias, debe saber decir y callar y hacer y omitir lo conveniente cuando es conveniente $\mathrm{y}$, naturalmente, donde es conveniente.

Ahora bien, la etimología, según parece, no tiene mayor importancia dentro de la teoría pragmática; sin embargo, en el campo del convencionalismo se hace válida, y es normal y necesaria dentro del naturalismo. En la Antigüedad, como ya se apuntaba, prevaleció el naturalismo y sin duda Isidoro es el ejemplo más claro de esa teoría.

Las cosas se comprenden por sus nombres, parece decir San Isidoro: sólo hay que ver qué tipo de relación existe cuando nombramos una cosa. La relación (I.29.3-5) puede ser de causa (ex causa), como en reges (reyes), que lo son porque recte agunt (actúan rectamente); o de origen (ex origine), como en homo (hombre), que nace de la humus (tierra); o de contrarios (ex contrariis), como lutum (lodo), llamado así de lavare (lavar), porque no es limpio. Puede existir una relación "puramente" fonética (ex vocibus), como en garrulus (charlatán), y puede darse también, más "convencionalmente", una relación por derivación de otros nombres (ex nominum derivatione), como prudens (prudente) a partir de prudentia (prudencia): nótese que, a diferencia de nuestro concepto actual de "derivación", el abstracto existe antes que el concreto en la concepción filosófica de la época de Isidoro. En fin, los nombres pueden venir también de otras lenguas (ex diversarum gentium sermone), principalmente del griego: desafortunadamente, tras la torre de Babel, la lengua primera y verdadera, un hebreo original, se había corrompido en muchas otras, de las cuales se conservaron como sagradas el hebreo, el griego y el latín (IX.I.1-3). El capítulo De etymologia (sobre la etimología) termina con la afirmación de que hay muchísimos nombres bárbaros y desconocidos para latinos y griegos, afirmación que, 
después de leer el tratado isidoriano, resulta difícil de creer: en éste, cada cosa (tierra, planta, animal, elemento, nombre propio, parte del cuerpo, región del mundo, etcétera) parece tener su nombre, y cada nombre, su etimología. El universo se explica a partir de las etimologías de los nombres de sus componentes; después de todo, el mundo es kosmos (belleza), porque "ninguna otra cosa más bella vemos con los ojos de la carne" (XIII.1.2).

Sería muy interesante analizar qué cosas, según Isidoro, han recibido sus nombres ex causis (por sus causas); cuáles, ex origine (por su origen), y cuáles, ex vocibus (por sus voces): quizá el orden del universo antiguo se nos mostraría más claramente; basten, por ahora, algunas muestras.

Como si por la palabra se ordenara el mundo, o porque es necesario manifestar la forma en que se explica el universo, Isidoro inicia su tratado con la Gramática. Para justificar el que en este artículo hable acerca de la significación sólo de las cosas, es decir, sobre nombres, veamos cómo define Isidoro el nombre y el verbo; este último no necesita etimología: el mundo está hecho de cosas, no de acciones:

Se llama nombre (nomen) como si fuera notamen, porque nos hace conocidas (notas) las cosa con su vocablo; en efecto, si no se conociera el nombre, desaparecería el conocimiento de las cosas... Se llama verbo (verbum $)^{9}$ porque suena al azotarse el aire (verberato aere), o porque esta parte se encuentra (versetur) frecuentemente en la oración. Pues los verbos son signos de la mente, con los cuales los hombres manifiestan sus pensamientos al hablar unos con otros. Como el nombre significa a la persona, así también el verbo significa el hecho y el dicho de la persona... ${ }^{10}$

\footnotetext{
${ }^{9}$ El término verbum designa tanto a la "palabra" en general, como al "verbo" de la oración.

${ }^{10}$ Isid., Etym., I.7.1: "Nomen dictum quasi notamen, quod nobis vocabulo suo
} 
En otra parte, San Isidoro dice:

Adán, por la primera vez, aplicó vocablos a todos los seres animados, llamando a cada uno por su nombre, a partir de su constitución externa, según la condición de la naturaleza que tenía. Pero los pueblos dieron vocablos a cada uno de los animales según su propia lengua... ${ }^{11}$

Quizá por ello, pienso, los nombres de los animales sean tan expresivos: valgan otros ejemplos de los distintos tipos de etimología isidoriana: la oveja (ovis) recibe su nombre ab oblatione (de la ofrenda), porque los antiguos sacrificaban ovejas; el cordero se llama agnus, porque reconoce (agnoscit) a su madre, y los cabritos se llaman haedi ab edendo (del comer), pues de pequeños son pinguissimi et saporis iucundi (muy grasosos y de sabor agradable); y se dice cuniculus quasi caniculus (conejo, como si fuera perrito), porque los conejos son atrapados por el ojeo de los canes (XII.I.9, 12, 13 y 24). El oso se llama ursus porque ore suo (con su propia boca) da forma a sus cachorros: dicen que las crías de oso son informes hasta que su madre los lame (XII.2.22); algún tipo de serpiente se llama colubrum (culebra) porque colit umbras (habita en las sombras) y otro, porque vi parit (pare sus crías con violencia) se llama vipera (IV.2 y 10). Las pulgas (pulices) reciben ese nombre porque de polvo (pulvere) se nutren (XII.V.15). El águila

res notas efficiat. Nisi enim nomen scieris, cognitio rerum perit... I.7.9: Verbum dictum eo, quod verberato aere sonat, vel quod haec pars frequenter in oratione versetur. Sunt autem verba mentis signa, quibus homines cogitationes suas invicem loquendo demonstrant. Sicut autem nomen significat personam, ita verbum factum dictumque personae...

11 Isid., Etym., XII.I.1-2: "Omnibus animantibus Adam primum vocabula indidit, appellans unicuique nomen ex praesenti institutione iuxta condicionem naturae sui serviret. Gentes autem unicuique animalium es propria lingua dederunt vocabula. Non autem secundum Latinam linguam atque Graecam aut quarumlibet gentium barbararum nomina illa imposuit Adam, sed illa lingua quae ante diluvium omnium una fuit, quae Hebraea nuncupatur... " 
(aquila) se llama así ab acumine oculorum (por la agudeza de sus ojos); las grullas (grues) tomaron su nombre de su propia voz, pues susurran con ese sonido; el cisne se llama olor porque es enteramente blanco, y en griego entero se dice holos: nadie recuerda un cisne negro, dice Isidoro (XII.7.10, 9 y 18).

También son expresivos, aunque no tanto, los nombres de las plantas; ellos indican, a veces, la utilidad de aquéllas: se dice haba como si fuera "faga" (faba quasi faga), del griego phagein, que es "comer", porque ésa fue la primera legumbre que comieron los hombres; las uvas (uvae) toman su nombre de que están llenas de jugo por dentro: son uvidas (húmedas); del verbo alere (alimentar) se deriva la palabra olus (hortaliza), porque los hombres se alimentaban de hortalizas antes de que comieran frutos y carnes; la lechuga (lactuca) se llama así o porque tiene abundancia de leche o porque hace que las mujeres que amamantan se llenen de leche (lacte), y el laurel (laurus) deriva su nombre de la palabra laus (loa), pues con este árbol se coronaban, en alabanza, las cabezas de los vencedores (XVII.4.3, 5.13, 10.2 y 11, y 7.2).

El ser humano también está determinado por los nombres: se llama vir (varón) de vis (fuerza o violencia), sea porque en él la fuerza es mayor que en las mujeres, sea porque obliga a la mujer por la fuerza, e Isidoro precisa: de aquí (vis) también viene virtus (virtud). La mujer (mulier) se llama así a mollitie (de la blandura), como si se dijera mollier, "habiéndose cambiado una letra y quitado otra" (XI.2.17 y 18). Se dice mater (IX.5.6), porque de ahí se forma algo, "como de la materia, pues la causa es el padre" (quasi materia, nam causa pater est). Al hombre, también lo determinan los nombres que designan las partes del cuerpo: la sangre (IV.5.6) recibe su nombre (sanguis) porque es suave (suavis), y por ello, los hombres en quienes este humor domina son dulces et blandi (suaves y afectuosos); los ojos llevan su nombre (oculi) quizá porque tienen una luz oculta (occultum lumen), y las orejas (aures), 
porque "beben" (hauriunt) las voces; las manos (manus) se llaman así porque están al servicio (munus) del cuerpo entero (XI.1.36, 46, 66).

El hombre habla y lucha: por un lado utiliza argumentaciones (argu/ment/ationes), que son como discursos de una mente astuta: quasi argutae mentis orationes (II.9.1); por el otro, participa en guerras, que se llaman bella y antiguamente duella, o porque son dos las partes que combaten, o por antífrasis, porque no son bellas, sino hórridas (XVIII.1.9).

También los pueblos han recibido sus nombres por alguna causa: los romanos y latinos derivaron su nombre del fundador de su estirpe, Romulus y Latinus (IX.2.84), pero los bárbaros tienen nombres más interesantes: los sajones (IX.2.100) se llaman así porque se trata de una raza dura y muy fuerte, como la roca (saxum); los francos (IX.2.101) toman su nombre $a$ feritate morum (de la fiereza de sus costumbres); los bretones o britanos (IX.2.102), porque son bruti (bestial, salvaje), y los galos (IX.2.104), de la palabra que en griego designa la leche, gala, por la blancura de su cuerpo. Germania, finalmente, recibe su nombre porque los germanos son enormes (immanes) de cuerpo y enormes de pueblos (IX.2.97), o por su fecundidad para engendrar pueblos (propter fecunditatem gignendorum populorum: XIV.4.4).

Suficiente para este espacio. Quizá se haya podido notar, en esta abigarrada y aleatoria selección de nombres, la firmeza con que Isidoro expone las etimologías: no duda en que cada nombre tiene un origen exacto; si acaso, por la mudanza propia de la naturaleza humana, duda en elegir entre varias etimologías igualmente "verdaderas". Quienes leyeron su tratado en la Antigüedad, estaban convencidos de su autoridad. ${ }^{12}$ Isidoro no

12 Al respecto, quizá valga como dato curioso esta cita de una página de Internet dedicada a San Isidoro, que lo propone como "patrón de Internet": "Las Etimologías de san Isidoro de Sevilla son más que etimologías, porque de nada más disponían en el siglo vII los estudiosos de cualquier materia... Eran a un 
inventa ni fabrica etimologías a su capricho: además de las relaciones que "naturalmente" se encuentran entre nombres y cosas, él se basa en fuentes, muchas de ellas implícitas, algunas manifiestas: Varrón, Plinio, Séneca, Lucrecio, Cicerón, San Agustín, Servio, Virgilio, Lucano, etcétera. Constantemente alude a las Sagradas Escrituras, porque está consciente de que todo nombre ha tenido su origen en la Creación y de que todas las cosas han surgido del pueblo elegido: el alfabeto hebreo fue el primer sistema de escritura; los poetas del Antiguo Testamento fueron los primeros hombres que hicieron versos; la lengua hebrea es la lengua primera. Finalmente, San Isidoro es un obispo y por algo se convirtió en un santo: su cristianismo es el fundamento de toda su obra. Por todo eso, Isidoro de Sevilla tiene autoridad.

Para nosotros, Isidoro abunda en etimologías curiosas e infundadas; para los destinatarios de su obra, sus etimologías están adecuadas precisamente a las circunstancias de su mundo y de su vida; mediante las etimologías, San Isidoro explica su universo.

En la Antigüedad, parecería que recurrir a la etimología de las palabras da fundamento al significado, da una especie de matiz científico al sentido de las palabras de una lengua: la etimología supone una relación entre las cosas y los nombres; es en cierta forma un intento de anular la arbitrariedad del signo lingüístico, la expresión de un anhelo por ordenar el caos, la

tiempo las razones de las palabras y de las cosas. Si alguna vez las cosas fueron guardadas por las palabras, eso ocurrió en las Etimologías de san Isidoro... Las Etimologías de san Isidoro, pues, fueron nuestra memoria universal, fácilmente accesible a todos. Nuestra memoria común, imagen de nuestra mente, hoy descansa en la red de búsquedas conocida por el nombre universal de "internet", a la que nos acercamos cada día en busca de lo que le falta a nuestro ánimo. La única, absolutamente la única memoria de todo Occidente durante siglos fueron las Etimologías de san Isidoro. No despreciemos su pequeñez comparada con la magnitud de la red llamada de internet; pues hasta ahora se encuentra mayor cúmulo de conocimiento humano y de ciencia en las Etimologías de san Isidoro que en toda la red de internet... (Mariano Arnal Arnal, www.elalmanaque.com). 
búsqueda de un significado del mundo, un remedio a la necesidad, tantas veces angustiante, de comunicar al otro lo que realmente queremos decir. No en balde Quintiliano, dentro de la enseñanza retórica, trata la etimología como un recurso de la "definición"13 y, en filosofía, los escolásticos colocan la explicatio terminorum al principio de cualquier quaestio. ${ }^{14}$

Actualmente, la etimología, a pesar de que tiene bases lingüísticas firmes, no nos sirve para explicarnos el universo ni para suprimir el caos. A los hablantes, muchas veces, las etimologías de algunas palabras les resultan tan "autoritarias" y tan "infundadas" como lo son, en la mayoría de los casos, las etimologías isidorianas: ¿cómo quedarán nuestras etimologías con otros catorce siglos de adelanto técnico y humanístico? No lo podemos siquiera imaginar.

Sin embargo, las etimologías todavía tienen sentido en nuestros diarios discursos. Cuando alguien, ahora, da la etimología de una palabra, lo hace para definir mejor un término, para explicar alguna cosa; a veces, para facilitar el aprendizaje de un vocabulario; a veces, para jugar con las palabras: también hoy, como en tiempos de San Isidoro, ese "alguien" se presenta como una autoridad: filósofo, filólogo, maestro, poeta. Pero no es preciso ser una autoridad para atreverse a delimitar con palabras un continuo de "cosas", para explicar el significado de algo, para que se comprenda el sentido de lo

\footnotetext{
13 Quint. I.VI.28-31: “Etymologia... uerborum originem inquirit... Haec habet aliquando usum necessarium, quotiens interpretatione res de qua quaeritur eget... Ideoque in definitionibus adsignatur etymologiae locus... Nonnumquam etiam barbara ab emendatis conatur discernere... Continet autem in se multam eruditionem... " ("La etimología... investiga el origen de las palabras... Ésta se hace necesaria cuantas veces el asunto que se inquiere precisa de una interpretación... Y por ello en las definiciones se da su lugar a la etimología... En ocasiones, también es utilizada para tratar de distinguir las palabras extranjeras de las correctas... Por otra parte, esta ciencia contiene mucha erudición...”)

${ }^{14}$ En latín, a esa explicación de términos se le da el nombre de sensus tituli (sentido del título) o de sensus quaesiti (sentido de lo que se pregunta). Cfr. Boyer, C., Cursus Philosophiae.
} 
que decimos. En cada situación del habla, en cada enunciación, los interlocutores son a fin de cuentas autoridades; la etimología, si la utilizamos cuando es conveniente, aclara, interesa y divierte, quizá porque aunque sabemos y percibimos que en la significación de las cosas reina el arbitrio, aún queremos encontrar en las palabras la relación mágica con las cosas que designan; tal vez aún deseamos que las palabras tengan un significado evidente, que indiquen las cosas por naturaleza.

\section{Bibliografía}

Aristote, Rhétorique (ed. y trad. de Médéric Dufour), Les Belles Lettres, París, 1991 (tomos I-II).

Boyer, Carolus S.I., Cursus Philosophiae, Desclée de Brouwer, Roma, 1940.

Diels, Herman, Die Fragmente der Vorsokratiker, Siebente Auflage herausgegeben von Walter Kranz, Verlagsbuchhandlung, Berlín, 1952-1954 (tomo II).

Gadamer, H.G., Wahrheit und Methode (Grundzüge einer philosophischen Hermeneutik), Tübingen, 1975.

Gorgias, Fragmentos (intr., tr. y notas de Pedro C. Tapia Z.), UNAM, México, 1980 (Bibliotheca Scriptorum Graecorum et Romanorum Mexicana).

Homero, Ilíada (intr., versión rítmica y notas de Rubén Bonifaz Nuño), UNAM, México, 1997 (Bibliotheca Scriptorum Graecorum et Romanorum Mexicana).

Horacio, Arte Poética (intr., versión rítmica y notas de Tarsicio Herrera Z.), UNAM, México, 1970 (Bibliotheca Scriptorum Graecorum et Romanorum Mexicana).

Isidoro de Sevilla, Etimologías, (ed. bilingüe; texto latino, versión española y notas por J. Oroz Reta y M. A. Marcos Casquero; intr. por M. Díaz y Díaz), BAC, Madrid, 1982.

Plato, Timaeus, Critias, Cleitophon, Menexenus, Epistles (trad. de R. G. Bury), Harvard Univ. Press-W. Heinemmann, CambridgeLondres, 1966 (p. 383 y ss.). 
Platón, Cratilo (intr., versión y notas de Ute Schmidt), UNAM, México, 1988 (Bibliotheca Scriptorum Graecorum et Romanorum Mexicana).

Puig, Luisa, La realidad ausente. Teoría y análisis polifónicos de la argumentación, UNAM, México, 2000.

Quintilien, Institution Oratoire (ed. y trad. de Jean Cousin), Les Belles Lettres, París, 1975-1978.

Tapia Zúñiga, Pedro C., "Gorgias, más allá del bien y del mal", Acta poetica 14-15, UNAM, México, 1993-1994, pp. 33-56. 
